\title{
NOTAS SOBRE O ENSINO DE FILOSOFIA NOS CURSOS DE GRADUAÇÃO NO SERVIÇO SOCIAL
}

\author{
Notes on the teaching of philosophy in the \\ Social Service graduation courses
}

\section{Antônio Alex Pereira de Sousa ${ }^{1}$}

RESUMO: Ministrar aulas de Filosofia exige esforço para lidar com uma diversidade de questões, como o conteúdo, a especificidade do lugar onde se ensinará e as especificidades do ensino de Filosofia. Nesse contexto, o presente artigo visa apresentar questões, informações e sugestões, aqui consideradas importantes, para aqueles que ensinam ou iniciaram a docência de Filosofia nos cursos de graduação em Serviço Social. A partir de documentos institucionais e analisando a legislação vigente sobre currículo e a grade curricular de várias instituições de ensino superior, foram sugeridas algumas propostas no ensino de Filosofia, as quais foram confrontadas com algumas formas efetivas de seu ensino. A elaboração do presente escrito teve por base a análise documental de projetos pedagógicos e ementas, muitos deles disponíveis na página digital de cada instituição. Das conclusões, tiramos que a maioria dos cursos de Serviço Social oferece a disciplina nas suas grades curriculares, tendo a Filosofia como um suporte necessário para a formação dos seus discentes. Contudo, há instituições que não oferecem a disciplina de Filosofia de forma presencial, pois em alguns casos ela é ofertada via educação a distância, sem nenhum cuidado com a Filosofia nem com o Serviço Social. Por isso, o professor de Filosofia, no âmbito do ensino da graduação do SS, deve observar o quê e como ensinar para que o seu ensino se fortaleça nas instituições de ensino superior e para que a formação dos assistentes sociais tenha a Filosofia como um saber necessário e potente ao seu fazer profissional.

Palavras-chave: Filosofia. Currículo. Serviço Social. Ensino de Filosofia.

\begin{abstract}
Teaching Philosophy classes requires an effort to deal with a variety of issues, such as the content, the specificity of the place where one will be taught, and the specificities of teaching Philosophy. In that context, the article aims to present questions, information and suggestions, considered important for those who teach or have started teaching Philosophy in undergraduate courses in Social Work. From institutional documents and analyzing the current legislation on curriculum and curriculum of several institutions of higher education, some proposals were suggested in the teaching of Philosophy, which were confronted with some effective

\footnotetext{
${ }^{1}$ Professor de Filosofia na Faculdade Ratio e na Secretaria de educação do Estado do Ceará. Mestrando em Filosofia (Profissional) pela Universidade Federal do Ceará, especialização em Filosofia pela Universidade Estácio de Sá e graduação em Filosofia pela Universidade Estadual do Ceará. E-mail: alexsousa.filosofia@gmail.com
} 
forms of its teaching. The preparation of this paper was based on the documentary analysis of pedagogical projects and course menus available in the digital page of each institution. From the conclusions, we observed that most Social Service courses offer discipline in their curriculum, with Philosophy as a necessary support for the training of their students. However, there are institutions that do not offer the discipline of Philosophy presential, since in some cases it is offered by way of distance education, without any care with Philosophy or Social Work. Therefore, the professor of Philosophy, within the scope of Social Service graduation teaching, should observe what and how to teach so that his teaching strengthens in higher education institutions and so that the training of social workers has Philosophy as a knowledge necessary and powerful to your professional doing.

Key-words: Philosophy. Curriculum. Social service. Teaching Philosophy.

\section{INTRODUÇÃO}

O ensino de Filosofia nos cursos de Serviço Social é reconhecidamente uma etapa importante na formação dos assistentes sociais. Presente em todos os currículos de forma indireta - na influência a outras disciplinas, como a Ética no Serviço Social, e na própria história do Serviço Social, através de ideologias, como a tomista - e de forma direta através de disciplinas filosóficas, esse saber milenar muito contribuiu e ainda fornece um amplo arsenal teórico para a compreensão dos problemas sociais que afligem a sociedade, bem como o entendimento sobre o que seja o homem, a ciência e seus devidos problemas.

Entretanto, ao analisar a organização de alguns currículos é perceptível que não há um alinhamento quanto aos conteúdos e problemas que devam ser pensados filosoficamente. Em outras palavras, não há uma padronização ou observância em diversas grades em torno do que deva ser ensinado nas disciplinas filosóficas.

Essa questão seria facilmente resolvida com o argumento de que cada instituição, por ter um projeto pedagógico ${ }^{2}$ específico, não se orienta por diretrizes gerais para definir os conteúdos trabalhados nas disciplinas de Filosofia ${ }^{3}$, ficando a

\footnotetext{
${ }^{2}$ O termo Projeto Político Pedagógico e Projeto Pedagógico serão utilizados de acordo com o modo utilizado por cada instituição. Não havendo acesso ao documento que o curso produziu, utilizaremos o termo Projeto Pedagógico.

${ }^{3}$ Importante ressaltar que diretrizes não significa necessariamente currículo. As diretrizes são como orientações para que se desenvolva algo. Contudo, delas se realizarem, como no caso o currículo, não segue um modelo específico. Sobre isso a LDB é clara a não definir a forma como as instituições de ensino, tanto da etapa básica quanto da superior, devam organizar seus currículos.
} 
cargo do corpo docente de cada instituição defini-lo. Além disso, estaria em consonância com as atuais diretrizes (MEC, 2002) que orientam a organização dos currículos para os cursos de SS através de núcleos de fundamentação da formação profissional, não por disciplinas.

Contudo, partindo de experiência própria na docência em um curso de Serviço Social em uma faculdade privada de Fortaleza, percebi que o argumento do corpo docente definir seu próprio currículo não responde necessariamente o problema da não padronização dos currículos ou da falta de atenção a sua organização. Quando se observa, por exemplo, cursos com pouco tempo de criação, que não tiveram um diálogo aprofundado sobre a definição do conteúdo presente nas disciplinas, vê-se que o professor de Filosofia, em muitos casos, trabalha de forma simplória a história da Filosofia e suas temáticas centrais, despotencializando a contribuição que esse saber milenar tem a dar na formação dos assistentes sociais. A lógica de organização da disciplina segue, desse modo, a ministradas nas graduações em Filosofia, tendo como eixo central a história da Filosofia, iniciando com o surgimento da Filosofia e principais filósofos gregos, passando pelo medievo, modernidade e terminando com a apresentação de alguns pensadores do século XX, que chamaremos aqui de contemporâneos.

Essa lógica da organização curricular, que já sofre uma crítica nos cursos de graduação em Filosofia (PORCHAT, 1999), pois se orienta quase exclusivamente através de método estrutural ${ }^{4}$ de pesquisa tomando como eixo central a história da Filosofia, estorva a criatividade do pensamento filosófico, podendo surtir nos cursos de Serviço Social efeitos contrários àqueles que pensamos ser o esperado de uma disciplina de Filosofia.

Entretanto, ressaltasse que a crítica aqui tecida à organização das disciplinas de Filosofia a partir de sua história não significa que o estudo por esse viés não possibilite um aprendizado e o que alguns chamam de experiência do pensamento

\footnotetext{
${ }^{4} \mathrm{O}$ método estrutural diz respeito a técnicas de leitura de textos filosóficos que proporcionavam ao aluno compreender a sua lógica interna, centrada numa abordagem analítica da história da Filosofia. $\mathrm{Na}$ leitura que aqui fazemos, o ensino de Filosofia nos cursos de Serviço Social seguiria essa lógica de ensino, que tem suas origens no Brasil na Universidade de São Paulo (USP) por influência francesa, de forma mitigada. Em outras palavras, se nos cursos de Filosofia aprende-se a ler textos filosóficos a partir do método estrutural, nos cursos de SS a orientação é a mesma, mas de forma bem menos rigorosa. Entretanto, esse método vem sofrendo duras críticas, por limitar o pensamento filosófico criativo. Uma dessas críticas veio de um dos maiores especialistas neste método, o professor Oswald Porchat. Para mais, ler a entrevista Discurso aos estudantes sobre a pesquisa em Filosofia proferida por Porchat em Salvador.
} 
(GALLO, 2012). Entendesse, desse modo, que a definição do que ensinar num curso deva considerar uma série de questões, como a especificidade da realidade aonde se ensinará Filosofia, das orientações curriculares, da subjetividade do professor e dos conteúdos vistos como importantes a ser ministrados pela comunidade acadêmica, especialmente a filosófica.

Partindo dessa seara, aqui o objetivo é entender como se dá a presença da Filosofia nos cursos de Serviço Social e pontuar questões que possam subsidiar docentes das disciplinas de Filosofia no que se refere à sua prática pedagógica no tocante aos conteúdos e aos objetivos. Para tanto, se faz necessário: explicar rapidamente as questões históricas e ideológicas que ligam a Filosofia e o Serviço Social; apresentar a forma de como o ensino de Filosofia está presente nos documentos de Estado que tratam do currículo, bem como as diretrizes para o ensino superior; e, por fim, analisar alguns currículos de cursos de Serviço Social que possam ser referência para nosso estudo ${ }^{5}$.

Problematizar a presença da Filosofia no currículo dos cursos superiores, sejam eles de exatas ou humanas, como o Serviço Social, é importante para mostrar a capacidade do pensamento filosófico em oferecer ferramentas para se compreender o presente. Além disso, sua especificidade conceitual é um instrumento necessário para o desenvolvimento de habilidades intelectuais imprescindíveis a qualquer indivíduo que adentra no ensino superior.

Pensar a forma como o ensino de Filosofia deva estar nas grades curriculares possibilita uma organização mais clara e responsável dos conteúdos a ser trabalhados com os discentes, evitando uma dispersão desnecessária e a reprodução de uma lógica organizativa de conteúdos que despotencializam a importância da Filosofia na formação acadêmica. Essa é a principal razão para o desenvolvimento desta pesquisa aqui apresentada. Neste momento, recorro à experiência que tive como professor de Filosofia em uma graduação de SS: na ementa de uma disciplina de 80 horas/aula ${ }^{6}$, além de ser composta por um conteúdo

\footnotetext{
${ }^{5}$ Analisaremos o currículo de seis instituições. Os cinco primeiros (UFRJ, PUC-SP, UFRGS, UFPE e UNB) são de cursos que foram considerados os melhores do Brasil pelo jornal Folha de São Paulo no ano de 2017 (RUF - Ranking Universitário Folha 2017), que considerou: avaliação do mercado; qualidade do ensino; existência de mestrado e doutorado; nota do Exame nacional de Desempenho dos Estudantes - ENADE; dedicação dos professores; avaliação dos docentes. Além desses, examinaremos o currículo da UECE, pois o pesquisador habita na cidade de Fortaleza e pode ter acesso a documentos do curso de Serviço Social mais antigo do Ceará.

${ }^{6}$ A disciplina da Faculdade Ratio, instituição que sou professor da disciplina de Filosofia, estava orientada para a história da Filosofia e modifiquei para o viés temático, onde muitas vezes o mesmo
} 
excessivo de História da Filosofia e uma diversidade de questões ontológicas, não tive orientação do quê e do como ensinar; bem como não havia nenhum tópico que possibilitasse uma discussão sobre a importância de pensar o Projeto Pedagógico, o currículo e a função da Filosofia no SS.

Para o desenvolvimento da pesquisa, foram analisados documentos que orientam a organização curricular dos cursos de Serviço Social, como a lei de Diretrizes e Bases da Educação (LDB), pareceres dados pelo Ministério da Educação (MEC) e artigos de associações, como a Associação Brasileira de Ensino e Pesquisa em Serviço Social (ABEPSS). Também serão examinados documentos que mostram a presença da Filosofia nos currículos, com ênfase nas grades curriculares de cursos das seguintes Instituições de Ensino Superior (IES): Pontifícia Universidade Católica de São Paulo (PUC-SP); Universidade Federal do Rio de Janeiro (UFRJ); Universidade Federal do Rio Grande do Sul (UFRGS); Universidade Federal do Pernambuco (UFPE); Universidade de Brasília (UNB); Universidade Estadual do Ceará (UECE) $)^{7}$.

\section{A FILOSOFIA NO SERVIÇO SOCIAL}

A Filosofia como saber científico está presente na história do Serviço Social no Brasil desde o seu nascimento. Através do tomismo característico da igreja católica, que fomentou a criação dos primeiros grupos e instituições preocupadas com o social, assim como do positivismo que tanto influenciou a formação da república brasileira, a Filosofia esteve presente no modo como os primeiros indivíduos preocupados com as questões sociais brasileiras pensavam a sociedade, o homem, o mundo e o Estado. Essa mesma influência, na segunda metade do século XX, passa a ser o pensamento do filósofo alemão Karl Marx (1818-1883).

\footnotetext{
filósofo era retomado durante o curso. Contudo, essa forma de ensino não contempla a forma de pensamento que temos como referência para o ensinar, que é a do pensamento por problemas filosóficos. A partir de problemas filosóficos de uma determinada realidade se organiza o currículo para atender as suas necessidades. Para mais sobre a organização curricular a partir de problemas ver a obra Metodologia do Ensino de Filosofia de autoria do professor Sílvio Gallo.

${ }^{7}$ A escolha da PUC-SP se deu por ser a primeira instituição no Brasil a ter um curso de SS. A UFRJ, UFRGS, UFPE e UNB foram escolhidas por terem, segundo o Ranking Universitário Folha de São Paulo 2017, os melhores cursos superiores dos Brasil, além do curso da própria PUC-SP, que está nesta lista. A escolha da UECE se deu pelo fato do pesquisador ser do Estado do Ceará, podendo ter acesso a documentos e outras informações da instituição que tem o curso mais de serviço social ais antigo do Estado.
} 
A presença da Filosofia nos cursos de Serviço Social, associada às influências citadas acima, se dá por meio do seu ensino em forma de disciplinas. Para pensar esta questão, será feita uma análise do como as disciplinas filosóficas estão nas grades curriculares dos cursos de Serviço Social. Será observado, inicialmente, o curso da PUC-SP, por ser a primeira instituição a oferecer a graduação em Serviço Social no Brasil e ser, reconhecidamente, um curso de referência em ensino e inovação.

$\mathrm{Na}$ PUC-SP, as disciplinas são descritas como subsídios para o Serviço Social: Fundamentos Filosóficos para o Serviço Social I e Fundamentos Filosóficos para o Serviço Social II (Currículo 2010). No Projeto Pedagógico ${ }^{8}$ do curso, assim está descrita a função das disciplinas:

A sua alocação no primeiro ano justifica-se na proposta de introduzir
o debate sobre a profissão desde a entrada do aluno no curso,
fornecendo base para o trabalho de Fundamentos Históricos-teórico-
metodológicos do Serviço Social (primeiro e segundo ano) e Ética.

A ementa das disciplinas da PUC-SP é exemplo de como a Filosofia pode dialogar com o Serviço Social de modo a potencializar as duas áreas. Não se inicia o estudo de Filosofia abordando seu nascimento, mas com conceitos importantes para o Serviço Social que são retomados no decorrer da disciplina, como a definição de Filosofia a partir das diferenças entre senso comum e ciência e dos conceitos de trabalho e cultura a partir da análise dos modos de produção, como realizados por Karl Marx. Na continuação da disciplina há um diálogo mais direto entre a história da Filosofia e o Serviço Social, onde se analisa o positivismo e o humanismo cristão, além da corrente fenomenológica e sua compreensão do sujeito. Por fim, há abordagem da leitura marxista e genealógica ${ }^{9}$ (Foucault).

O curso de Serviço Social que no ranking da Folha de São Paulo (2017) está em primeiro lugar é o da Universidade Federal do Rio de Janeiro (UFRJ). Diferente do curso da PUC-SP que tem duas disciplinas, nela só há uma intitulada Filosofia e Serviço Social, com 60 horas/aula. Na ementa disponibilizada no site do curso, observa-se que a organização dos assuntos está bem delimitadas e não se exige um estudo de toda a história da Filosofia, já que focam em questões específicas para o curso. Na ementa, vê-se que o objetivo é compreender a "Relevância da

\footnotetext{
${ }^{8}$ Tivemos acesso ao Projeto Pedagógico e a ementa da disciplina através de diálogo via e-mail com a vice-coordenadora do curso, profa. Dra. Elizabeth de Melo Rico.

${ }^{9} \mathrm{Na}$ ementa da disciplina há obras de Gilles Deleuze (1925-1995) e Giorgio Agamben (1942), mas somente o termo genealogia, referente a Michel Foucault (1926-1984), é citado.
}

Cadernos Cajuína, V. 4, N. 2, 2019, p.04 - 20. 
Filosofia para o Serviço Social. Tradições filosóficas que incidiram no Serviço Social: positivismo, pragmatismo, neotomismo, fenomenologia e marxismo".

Dos cursos de Serviço Social analisados, o da Universidade Federal do Rio Grande do Sul - UFRGS, que têm o terceiro melhor curso do Brasil, não tem disciplina que trabalhe diretamente os conteúdos filosóficos. A organização curricular desta instituição segue a definida nas orientações curriculares do MEC de 2002, que não expressa quais disciplinas devam existir, mas afirma que o currículo deva se orientar pelos núcleos, que são: Núcleo de fundamentos teórico-metodológicos da vida social; Núcleo de fundamentos da formação sócio histórica da sociedade brasileira; e, Núcleo de fundamentos do trabalho profissional (MEC, 2002). Nas outras instituições analisadas neste trabalho há pelo menos uma disciplina de Filosofia, estando sempre no núcleo de fundamentos teóricos, mas não há referência à Filosofia em nenhum núcleo no currículo da UFRGS.

Poder-se-ia dizer que a disciplina Fundamentos históricos, teóricos e metodológicos do Serviço Social supriria essa ausência, já que as obras como Convite a Filosofia de Marilena Chauí e Serviço Social e Filosofia: das origens a Araxá de Antônio Geraldo de Aguiar são citadas na bibliografia de sua ementa e que, por isso, a Filosofia daria esse suporte histórico, teórico e metodológico. Contudo, se assim fosse, esta disciplina deveria estar no primeiro núcleo, não naquele que a função principal é dar suporte ao trabalho profissional. Neste sentido, creio poder afirmar que a referência a essas obras em bibliografias não supre a ausência de uma disciplina como a Filosofia.

A única universidade do Nordeste que têm um dos cinco melhores cursos de Serviço Social do Brasil, segundo o ranking citado, é a Universidade Federal do Pernambuco - UFPE. No curso desta instituição há duas disciplinas de Filosofia com 60 horas/aula cada, Introdução à Filosofia I e II. O Relatório perfil curricular, disponível no site do curso, apresenta uma ampla possiblidade de trabalho do conteúdo filosófico, mas a primeira disciplina tem um objeto mais introdutório, sendo trabalhada uma diversidade de temas de filosofias, além da sua definição, como se lê na ementa: "várias conceituações da filosofia: das origens históricas às hodiernas concepções do saber e fazer filosófico. o problema lógico e metodológico. o problema antropológico. tópicos específicos de filosofia".

$\mathrm{Na}$ Introdução à Filosofia II, já há uma organização para o trabalho com a história da Filosofia. Sem especificar quais filósofos devam ser estudados, nem as 
correntes filosóficas que mais dialogaram e se relacionam com o Serviço Social, a segunda disciplina abre diversas possibilidades que se tornam até mesmo muito gerais. "Estudo dos sistemas filosóficos nas idades antiga, média, moderna e contemporânea, destacando o pensamento dos principais filósofos”. Quanto à organização do currículo segundo a organização proposta pelo MEC em 2002 em núcleos, não tivemos a possibilidade de verificar, já que o projeto pedagógico não estava disponível na página eletrônica do curso.

Por sua vez, o Serviço Social na Universidade de Brasília - UNB - tem somente uma disciplina de Filosofia, com 60 horas/aula, intitulada Introdução à filosofia. Segundo o Projeto Político Pedagógico do curso esta disciplina "deve possibilitar a reflexão filosófica como possibilidade de apreensão da totalidade social, estabelecendo conexões entre ciência, verdade e método e as relações entre a filosofia e a política". Na ementa da disciplina se observa que não há uma organização em torno da relação entre Serviço Social e Filosofia, mas sim as questões em torno do surgimento e da história da Filosofia. Contudo, no documento está expresso que a ementa é do departamento de filosofia, o que nos faz pensar que ela pode não ter sido elaborada junto ao corpo docente do Serviço Social.

O curso da UECE oferece duas disciplinas que são pré-requisito para outras ${ }^{10}$ : Fundamentos de Filosofia e Correntes Modernas da Filosofia das ciências (Currículo 2017). A disciplina de Fundamentos de Filosofia aborda questões mais gerais e comuns no campo filosófico, apresentando questões que em várias áreas de saber podem ser objeto de análise: "Desdobramentos das correntes filosóficas: empirismo, racionalismo, idealismo, dialética, marxismo, estruturalismo. Abordagem pluralista do pensamento filosófico". Já a Correntes Modernas da Filosofia das Ciências tem como objetos de estudo as correntes filosóficas que foram e ainda são importantes para se compreender as questões e os problemas sociais. Observa-se que são correntes e questões filosóficas características dos séculos XIX e XX: "Dialética, Neopositivismo, Fenomenologia e Hermenêutica. Discussão sobre a ideia de Estado, o método científico, o conhecimento e interpretação".

Em currículos anteriores do curso da UECE havia mais disciplinas que tinham a Filosofia diretamente como objeto de estudo. Esses são os casos dos currículos aprovados nos anos de 1990, 2006 e 2016 que tinham as disciplinas: Fundamento

\footnotetext{
${ }^{10}$ As disciplinas são, consecutivamente, Teoria Política, Política Social e Ética Profissional em Serviço Social.
} 
de Filosofia, que mantém a mesma nomenclatura até hoje; Filosofia I (1990), que se transformou em Correntes Modernas da Filosofia (2006 e 2016); e Filosofia II (1990), que se transformou em Correntes Modernas da Filosofia das Ciências (2006 e 2016). Hoje, no currículo aprovado em 2017, há duas disciplinas, como citado anteriormente.

Mesmo com essa mudança, é possível observar que desde seu início o curso de Serviço Social da UECE tem a Filosofia como saber basilar na formação de seus discentes. No currículo mais antigo acessado, que orientava o curso nos anos anteriores a 1982, há na grade as disciplinas de Filosofia I e Filosofia das ciências, as quais tinham em suas ementas questões gerais, não tão específicas quanto as que organizam o currículo no presente. Por exemplo, a Filosofia I tinha como objetivo "proporcionar aos alunos os conhecimentos básicos e a criação de um espírito crítico e desenvolver num todo coerente a formação filosófico-humanista". Já na ementa do programa da disciplina Filosofia das ciências se encontra a seguinte delimitação:

A especificidade da filosofia da ciência, sua relação com gnosiologia e epistemologia. O processo de aperfeiçoamento e mudança da ciência tradicional para a ciência hoje. O desenvolvimento do pensamento filosófico-XXXXXXXX científico e sua relação ao social. Projetos epistemológicos na contemporaneidade. ${ }^{11}$

Esta breve história da presença da Filosofia no currículo da UECE, bem como o currículo dos cursos das outras universidades, com exceção da UFRGS, mostra a importância dada à Filosofia na formação dos assistentes sociais, já que sempre esteve presente na grade curricular do curso. Mesmo com questões passíveis de críticas, como as generalizações e não especificações do conteúdo, bem como um movimento de retirada de disciplinas de Filosofia em um determinado momentos e adição em outro, o que mostra uma volatilidade, sempre houve um diálogo entre a Filosofia e o Serviço Social na grade curricular do SS da UECE.

No presente, a formação profissional de assistentes sociais no Brasil tem como referência curricular documentos de organizações acadêmicas como a ABEPSS e instituições governamentais como o Ministério da Educação (MEC). No contexto da elaboração e aprovação da LDB, no ano de 1996 a ABEPSS $^{12}$ aprovou

\footnotetext{
${ }^{11} \mathrm{O}$ trecho "pensamento filosófico-xxxxxxxx" na citação segue como está no documento fornecido pela secretaria da graduação em serviço Social da UECE.

${ }^{12}$ A Associação Brasileira de Escolas de Serviço Social (ABESS) mudou em 1996 seu nome para Associação Brasileira de Ensino e Pesquisa em Serviço Social (ABEPSS). O motivo foram a "defesa
} 
em assembleia a proposta de Diretrizes Gerais para o Curso de Serviço Social, documento que deu base à construção das Diretrizes que orientam atualmente os currículos dos cursos de graduação de Serviço Social.

Contudo, para chegar às Diretrizes de hoje houve diversas mudanças, como a realizada em 1999 pela Comissão de Especialistas de Ensino em Serviço Social do MEC e a ocorrida em 2002, também elaborada pelo MEC. Se nas duas primeiras há uma explicitação dos conteúdos, nesta última há a ausência quanto a sua definição, deixando menos explícito o que especificamente deveria ser ministrado, dando abertura a interpretações diversas sobre como o currículo deve ser organizado. Para explicitar essas mudanças, seguem as orientações quanto ao ensino de Filosofia presente nos três documentos:

- Documento ABEPSS (1996): Filosofia: Os fundamentos ontológicos do ser social. A dimensão da sociabilidade, trabalho e alienação. As formas de consciência: política, ciência, religião, moral e arte. As atuais reflexões éticas sobre a ciência e suas repercussões no mundo do trabalho. Correntes filosóficas e suas influências no Serviço Social.

- Documento MEC (1999): Filosofia - Principais correntes filosóficas no século XX (marxismo, neotomismo, neopositivismo, fenomenologia) e suas influências no Serviço Social.

- Documento MEC (2002): núcleo de fundamentos teórico-metodológicos da vida social, que compreende um conjunto de fundamentos teóricometodológicos e ético-políticos para conhecer o ser social.

Percebe-se que as mudanças são significativas e têm efeitos diretos nos conteúdos a ser ministrados nas disciplinas, especialmente a de Filosofia. $\mathrm{Na}$ primeira orientação de 1996 há uma diversidade de temas a seres apresentados nas aulas de Filosofia, especificando somente algumas correntes de pensamento, como as filosofias que têm o materialismo dialético como fundamento (ontologia do ser social, trabalho e alienação) e as correntes filosóficas que influenciaram o Serviço Social, incluindo o já citado materialismo dialético.

dos princípios da indissociabilidade entre ensino, pesquisa e extensão e da articulação entre graduação e pós-graduação, aliada à necessidade da explicitação da natureza científica da entidade, bem como a urgência da organicidade da pesquisa do seu interior". Para mais informações sobre a história da ABEPSS, ver a página www.abepss.org.br. 
No documento de 1999 há uma redução de conteúdos e objetivação das correntes filosóficas que correspondem à exposição mais explícita do último tópico da orientação da ABEPSS de 1996: Correntes filosóficas e suas influências no Serviço Social. Se na formulação de 1996 não estava explicitas as correntes e os "filósofos" a serem estudados na disciplina de Filosofia, no documento do MEC de 1999 há orientação direta do que nos cursos de Serviço Social as disciplinas de Filosofia deveriam tratar: marxismo, fenomenologia, neotomismo e neopositivismo.

Nas Diretrizes formuladas pelo Conselho Nacional de Educação (CNE) e Câmara Superior de Educação (CES), documento aprovado pelo MEC em 2002, há uma definição incerta dos conteúdos a serem ministrados em todas as disciplinas que outrora estavam presentes nos documentos de 1996 e 1999. Ele parte da compreensão de que a organização curricular deve se "sustenta-se no tripé dos conhecimentos constituídos pelos núcleos de fundamentação da formação profissional" (MEC, 2002), onde a Filosofia, assim compreendo, encontrar-se-ia no núcleo acima citado, já que proporciona os "fundamentos teórico-metodológicos e ético-políticos para conhecer o ser social" (MEC, 2002).

Essa mudança gradativa na organização curricular, chegando até mesmo à inexistência de termos que de forma clara mostre a necessidade de uma disciplina como a Filosofia, não necessariamente deve ser visto como algo ruim. Se tomarmos como exemplo a história do currículo do curso de Serviço Social da UECE se observa que houve um amadurecimento quanto aos conteúdos ministrados nas disciplinas, deixando mais claro os temas e as correntes filosóficas trabalhadas.

Entretanto, quando observado no plano macro, essas mudanças podem ter efeitos negativos, como o apagamento e desqualificação da Filosofia nos currículos. Analisando a realidade de Fortaleza - $\mathrm{CE}^{13}$, observei que o currículo de muitos cursos de graduação em Serviço Social, oferecidos por faculdades particulares, só dispõe de uma disciplina de Filosofia, com média de 60 a 80 horas de aulas por semestre. Há casos em que a disciplina é ministrada por meio da educação à distância, EAD, com temáticas que não cooperam de forma direta com a formação do assistente social, nem mesmo estando próximo ao que as diretrizes orientam.

\footnotetext{
${ }^{13}$ Analisamos a grade curricular nas páginas eletrônicas e os projetos pedagógicos, quando havia, de sete cursos de Serviço Social oferecidos em Fortaleza por instituições privadas na modalidade presencial, que são: Unifametro, Faculdades Cearenses, Faculdade Rodolfo Teófilo, Estácio, Uninassau, Faculdade Ratio e UniAteneu. Esta última oferece uma disciplina de Filosofia cujos temas centrais são Lógica e Ética.
} 
Desse modo, o que pode ser um meio de diversificação da pesquisa, pode transformar-se numa armadilha que prejudica principalmente os discentes. Outro efeito negativo que as diretrizes de 2002 aprovadas pelo MEC têm é o verificado no currículo do curso de Serviço Social da UFRGS, no qual a Filosofia pode estar tão "dispersa" inexiste no currículo dessa instituição, considerada uma das melhores do Brasil.

Uma pergunta que se poderia colocar diante do resultado positivo de um curso como o da UFRGS é se há a necessidade do ensino de Filosofia na formação acadêmica dos assistentes sociais. Nossa resposta é sim, e por diversos motivos. A Filosofia possibilita uma compreensão de totalidade da realidade social. Muitos dos cientistas políticos, dos antropólogos, dos sociólogos e demais cientistas que são colocados como importantes na formação dos assistentes sociais lançam mão dos saberes filosóficos para criarem suas obras. Desse modo, o aluno que tem acesso ao conteúdo filosófico, articulado com o Serviço Social, de forma organizada e atenta às questões locais, terá a possibilidade de compreender o micro e o macro da realidade social com segurança e responsabilidade.

Como compreender Marx sem Hegel? Como entender o positivismo sem a leitura dos filósofos racionalistas e empiristas? Como apreender os métodos de trabalho social no presente sem ter acesso ao que filósofos fenomenológicos afirmaram? Como saber com profundidade a leitura de mundo daqueles que iniciaram o Serviço Social, os quais muito beberam da leitura tomista de mundo? Como olhar para o presente sem ter uma visão de poder que observa as micro instâncias de poder, como a visão foucaultiana? E poderíamos exemplificar mais.

Com isso não queremos dizer que a Filosofia (metafísica) seja, como disse Descartes, a raiz que dá sustentação a todos os outros saberes (1997, Pag. 22). Mas não podemos deixar de pontuar a importância que a filosofa tem na constituição de uma formação sólida com recursos teóricos, metodológicos, éticos e políticos que nenhuma outra disciplina sabe proporcionar.

Além disso, a Filosofia trata de conceitos que colocam em xeque a ideia de verdade, que está ligada à concepção de totalidade e é a base para a constituição de discursos científicos com alcance em toda a sociedade. A discussão acerca da verdade na Filosofia, ou mesmo uma crítica à ela, como é característico de filósofos contemporâneos, possibilita uma leitura radical da vida social. A ética e a política são extremamente beneficiadas pelas leituras filosóficas. 
Tudo isso mostra a importância que a Filosofia tem na formação discente de qualquer curso, em especial no Serviço Social. Contudo, uma última consideração sobre a importância da Filosofia se verifica na sua capacidade de possibilitar o que Sílvio Gallo (2012) chama de experiência do pensamento. A vivência real da capacidade criativa humana a partir do estudo e da criação de conceitos. Os conceitos filosóficos possibilitam que em nós seres humanos haja uma vivência do pensamento totalmente diferente do que há em outros saberes. Essa experiência visa a criação de novos conceitos que possibilitariam a ampliação do estudo de uma realidade social ou humana. Somente a Filosofia, por sua especificidade conceitual, que se difere da arte por produzir afetos e da ciência que produz fórmulas, nos dá uma dimensão criativa que possibilita uma mudança radical em nossa humanidade.

Assim, a observância às questões acima pontuadas sobre a presença da Filosofia, na forma de disciplinas nos currículos dos cursos de Serviço Social, deve ser utilizada como argumento para que órgãos fiscalizadores, como os Conselhos de Serviço Social e o MEC, ajam para impedir que cursos superiores, principalmente de instituições particulares, formem profissionais sem um suporte teórico que possibilite ao discente ter uma noção ampla da realidade social e da produção científica produzida pelos seres humanos.

\section{CONCLUSÃO}

De modo ainda germinal, o presente artigo analisou a presença da Filosofia nos currículos dos cursos de Serviço Social, fazendo um recorte nacional (UFRJ, PUC-SP, UFRGS, UFPE, UNB) e um local (UECE). A partir do exposto, consideramos que o professor de Filosofia de uma graduação em Serviço Social deve observar, antes de sua prática pedagógica, como o saber que domina - no caso a Filosofia - precisa ser ministrado, observando as diretrizes curriculares que orientam o curso em que leciona, atendo-se a quais problemas e correntes do pensamento filosófico são importantes para a formação do acadêmico.

Desse modo, o professor precisa também observar qual a proposta pedagógica do curso em que ministra a disciplina. Esta tarefa demanda tempo e disponibilidade, além de um diálogo com os outros docentes do curso, haja vista as especificidades e características que possam não estar explícitas no documento ou mesmo a existência de professores que não dialogam com a proposta do curso. 
Partindo desse ponto, é importante que o filósofo que dará aulas para futuros assistentes sociais observe as diretrizes nacionais que orientam os currículos. Geralmente as propostas pedagógicas, quando realizadas de modo atento e com participação do corpo docente, amparadas também por estudos, contêm essas informações sobre as diretrizes e articulam a grade curricular a elas.

Contudo, esse processo não é desenvolvido do modo adequado pelo colegiado da maioria dos cursos de Serviço Social, e tomamos como exemplo a realidade de Fortaleza. Analisando o currículo das principais faculdades particulares que oferecem graduação em Serviço Social na capital cearense, vê-se como não há, em sua maioria, uma preocupação curricular quanto ao ensino de Filosofia. Encontramos, por exemplo, cursos que oferecem disciplina sem orientação, sem uma ementa ou resumo no projeto pedagógico e muito menos a definição do que seria ministrado.

Outro problema detectado foi o descuido com a disciplina de Filosofia na oferta através da modalidade EAD, que muitas instituições passaram a usar devido a portaria aprovada pelo MEC em 2016 que permite as instituições de ensino superior com curso presencial ter $20 \%$ do seu currículo na modalidade a distância. Nesse contexto, que tem a faculdade Ateneu em Fortaleza como exemplo, os temas centrais da Filosofia giravam em torno da Lógica e da Ética. Contudo, somente o tema da Ética dialogava em muitos pontos com o Serviço Social, mas o tema da Lógica não fazia referência clara e significativa às diretrizes curriculares para que fosse ministrada, parecendo que a disciplina de outro curso foi utilizada para contemplar a "exigência" da Filosofia no currículo do curso de Serviço Social. No caso dessa suspeita ser verdadeira, fica demonstrado um completo descaso com a formação dos estudantes. Ficando somente nesses dois exemplos, é possível constatar a falta de atenção ao currículo, bem como a falta de fiscalização pelas instituições responsáveis que permite aberturas para que a formação de assistentes sociais sofra com o empobrecimento teórico-filosófico necessário à formação.

Outra questão que pode surgir da nossas considerações acerca do currículo de graduações em SS seriam as nossas considerações em torno das diretrizes curriculares, que poderiam ser vistas como uma delimitação do que todos as graduações devem oferecer, atingindo a liberdade de cátedra presente na constituição federal de 1988, artigo 206, onde diz que o ensino deve ter como 
princípios a "liberdade de aprender, ensinar, pesquisar e divulgar o pensamento, a arte e o saber (...) pluralismo de ideias e de concepções pedagógicas".

O professor universitário, desse modo, deve ter liberdade quanto ao que pesquisa e ensina, não podendo ser limitado por um currículo ou diretrizes. Entretanto, esta questão se mostra resolvida quando há diálogo entre os docentes e a constituição de um projeto pedagógico que contemple a diversidade do colegiado no que tange a suas especificidades e objetos de pesquisas, que em algum momento dialoga com as diretrizes curriculares nacionais.

Por fim, aquele que ensinará Filosofia para os estudantes de Serviço Social deve preocupar-se também com a especificidade da Filosofia que é a questão conceitual. O trabalho filosófico a partir de conceitos que são criados em decorrência do enfrentamento do filósofo com os problemas filosóficos, abrange dois pontos importantes. O primeiro é o próprio conteúdo, que deve ser adequadamente escolhido para ser ministrado nas disciplinas. O segundo é a preocupação com o pensar filosófico. É preciso que os acadêmicos em SS, assim como os de qualquer curso que dialogue com a Filosofia, percebam que toda reflexão filosófica surge de um problema e que aí se inicia a reflexão filosófica. Essa busca surge da falta/ausência de uma resposta ao questionamento filosófico.

Com isso, pensamos que as considerações do presente texto possam colaborar com aqueles filósofos que estão na função de ensinar Filosofia para os estudantes de Serviço Social, proporcionando a eles um olhar crítico sobre o currículo, as diretrizes curriculares, a especificidade do professor e da Filosofia. $O$ docente que parte dessas considerações iniciais terá, possivelmente, mais subsídios para ministrar boas aulas de filosofias atendendo as necessidades teóricometodológicos e ético-políticos que a profissão de assistente social exige, além de atentar para a especificidade da Filosofia que é a criação de conceitos, possibilitando uma real experiência do pensamento.

\section{REFERÊNCIAS}

AGUIAR, Antônio Geraldo. Serviço social e filosofia: das origens a Araxá. 4.ed. São Paulo: Cortez, 1985.

BRASIL. Constituição (1988). Constituição da República Federativa do Brasil. Brasília: Senado, 1988.

DESCARTES, René. Princípios de Filosofia. Lisboa: Edições 70, 1997. 
RICO, Elizabeth de Melo. Projeto Pedagógico do Curso de Serviço Social da PUC-SP. [mensagem pessoal]. Mensagem recebida por <alexsousa.filosofia@gmail.com> em 17 dez. 2018.

FACULDADE RODOLFO TEÓFILO. Curso de Serviço Social. Disponível em: https://www.frt.edu.br/graduacao/servico-social/. Acesso em: 17 de dezembro de 2018.

FACULDADES CEARENCES. Matriz curricular. Disponível em: http://ww2.faculdadescearenses.edu.br/pdf/matriz/SERVICOSOCIAL-2014.pdf.

Acesso em: 17 de dezembro de 2018.

FALCULDADE ESTÁCIO. Curso de Serviço Social. Disponível em: http://portal.estacio.br/graduacao/servi\%C3\%A7o-social. Acesso em: 17 de dezembro de 2018.

FATE. Projeto Pedagógico Serviço Social. Disponível em: $<$ http://fate.edu.br/documentos/projeto-pedagogico-bacharelado-servico-social.pdf $>$ Acesso em: 17 de dezembro de 2018.

GALLO, S. Metodologia do ensino de Filosofia: uma didática para o ensino médio. Campinas, 2012.

MEC. Portaria no 1.134, de 10 de outubro de 2016. Brasília, DF, n. 196, 11 out. 2016. Seção 1, p. 21.

MEC. Diretrizes Curriculares da ABEPSS. Brasília, DF, 26 fev.1999.

MEC. LDB - Lei no 9394/96, de 20 de dezembro de 1996. Estabelece as diretrizes e bases da Educação Nacional. Brasília: MEC, 1996.

MEC. Parecer CNE 1363/2001. Brasília, DF, 25 jan. 2001. Seção1, Pag. 60.

MEC. Portaria № 1.134. Brasília, DF, no 196, 11 out. 2016. Seção1, Pag. 21.

MEC. Resolução CNE/CES. Brasília, DF, № 15, 13 de Mar. de 2002.

PORCHAT, Oswald. Discurso aos estudantes sobre a pesquisa em Filosofia. Dissenso - Revista de Estudantes de Filosofia, São Paulo, № 2, p. 131-140. 1ํㅡㄴ sem. 1999.

UNB. Projeto Pedagógico do Curso de Graduação em Serviço Social Diurno. Disponível em: $<$ https://docs.google.com/file/d/0B 7sBWdcQLRKc1V4VWcyMHN2c28/edit> Acesso em: 15 de dezembro de 2018.

UNB. Projeto Pedagógico do Curso de Graduação em Serviço Social Noturno. Disponível em: 
<https://docs.google.com/file/d/0B 7sBWdcQLRKNXBoV21xdzduLXM/edit> Acesso em: 15 de dezembro de 2018.

UNIFAMETRO. Matriz curricular Serviço Social. Disponível em: http://www.fametro.com.br/cvtt/wp-content/uploads/2018/03/servico-social.pdf. Acesso em: 17 de dezembro de 2018.

UNINASSAU. Curso de Serviço Social. Disponível em: https://vestibular.uninassau.edu.br/Curso.aspx?Cursold $=83 \&$ CursoUnidadeld $=1019 \&$ Menuld=1\&Cidade=Recife\&UF=PE. Acesso em: 17 de dezembro de 2018.

UFRGS. Proposta de Reforma do Projeto Político-Pedagógico do Curso de Serviço Social <http://www.ufrgs.br/psicologia/graduacao/servico-social/curso1/projeto-pedagogico-1> Acesso em: 15 de dezembro de 2018.

UFPE. Relatório Perfil Curricular da Graduação em Serviço Social. Disponível em:<https://www.ufpe.br/documents/39390/0/servico social perfil 1404.pdf/537eb08 2-ae13-4b9f-b8d2-6a100caa1dcb > Acesso em: 15 de dezembro de 2018.

UFRJ. Departamento de Fundamento do Serviço Social. Disponível em: $<$ http://ess.ufrj.br/images/graduacao ess/DisciplinasFundamentos junho2017 final.p df> Acesso em: 15 de dezembro de 2018. 